\title{
FROM MODELLING MICROGRID TO CREATING SMART GRID
}

\author{
Michal IVANČÁK, Juraj KURIMSKÝ, Jakub URBANSKÝ \\ Department of Electric Power Engineering, Faculty of Electrical Engineering and Informatics, \\ Technical University of Košice, Letná 9, 04200 Košice, Slovak Republic, tel. +421 556023560 , \\ E-mail: michal.ivancak@tuke.sk
}

\begin{abstract}
Smart Grid or intelligent networks are the most frequently mentioned topic currently. We can say that research in this area is highly actual. This paper describes the impact of intelligent network elements on the part of a village or microgrid. The modell examines the effect of electric vehicle charging on the stability of distribution network operation. In addition to the chargers, the modell also features renewable sources, which are an inseparable part of the smart grid.
\end{abstract}

Keywords: smart grid, microgrid, RES, e-car, e-car charging, distribution system.

\section{INTRODUCTION}

In these days is the word "Smart" trendy term. It usually refers to different products with an increasing degree of computing power. Smart products such as smartphone, smart TV, or other intelligent electronics with a variety of features and applications are now very popular. Electricity is currently a strategic "raw material" and its importance in the future years is growing. For this reason, increasing emphasis is placed on the stability, safety, and security of the electricity supply to end customers. Therefore, the computerization is increasingly being introduced into the electricity system during the time. Very popular is also the new term "Smart Grid".

The many projects, articles, and publications focus on the theme of Smart Grid, as well as international and national conferences. Despite the enormous popularity, there is wide inconsistency in the definition of this term. Nevertheless, Smart Grid is often referred also to as the network capable of using more renewable energy sources and distributed production than the current network.

Comprehension of the current Smart Grid network is rather difficult and from costs perspective expensive. It is a long-term process that binds capital over many years. Therefore, it requires a strong commitment from all stakeholders. Besides, it is still not fully verified how the individual technologies within Smart Grid will work together. [1][2]

\section{IMPLEMENTATION OF THE SMART GRID}

Smart Grid networks have the following features and benefits over classic networks. The most significant difference is the different network topology due to the inclusion of distributed production that causes different energy flow directions. The change is also thanks to the new technologies, two-way communication and the presence of active elements and sensors throughout the system, self-monitoring as well as rapid detection and localization of failures.

Thanks to new technologies, higher reliability, better security, greater convenience for customers, and higher efficiency in the use of electricity are expected. Intelligent systems also envisage semi-automatic renewal and autoregeneration as well as adaptive protection and isolation of a potential problem. Customers are thus provided with the integration and provision of new services.

From the distribution point of view, it is the use of centralized resources along with decentralized resources.

Decentralized sources of small capacities deployed across Europe are in line with the European Union's commitment and commitment to increasing its share of renewable energy production to $20 \%$ by 2020 . A high degree of automation in distribution and transmission systems is expected to reduce system losses and the associated increase in ecology, economy and operational efficiency as well as support for scattered production along with the development and research of new management methods, results. [3][4]

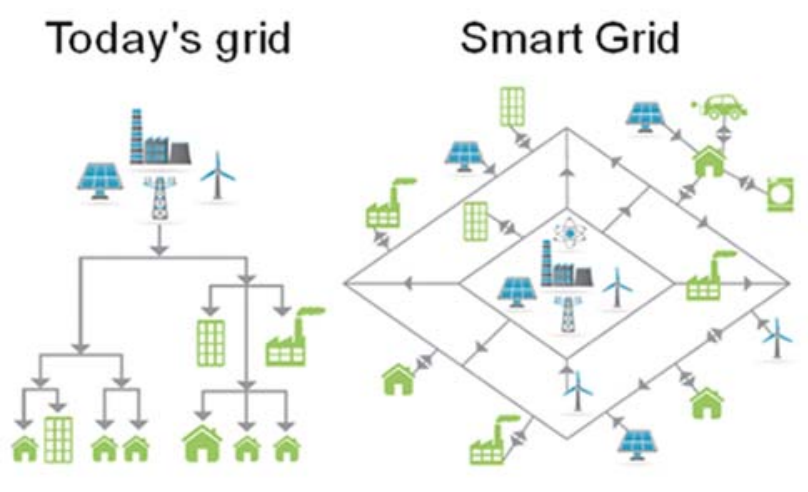

Fig. 1 Figure caption

\section{METHODS}

The main element used to create this article is the simulation program in which the network was modelled. Specifically, it is a network that represents a part of a village from Eastern Slovakia. In this program, the parameters of the network were considered as values of individual household consumption, parameters of power lines, and lengths between sampling and also parameters of power transformers. These data were static, creating the bases on which the analysis was conducted. [7]

\subsection{Description of used elements}

As mentioned above, several electrical elements were used in the simulation program. Several elements of smart 
grids, including PV panels and electric vehicle chargers, have been added to the core network elements. The number of elements used in the program can be seen in Table 1.

Table 1 An overview of the elements used

\begin{tabular}{cc}
\hline \hline $\begin{array}{c}\text { TYPE OF USED } \\
\text { ELEMENT }\end{array}$ & $\begin{array}{c}\text { NUMBER OF USED } \\
\text { ELEMENT }\end{array}$ \\
\hline \hline Line & 137 \\
\hline Nodes & 89 \\
\hline Loads & 73 \\
\hline $\begin{array}{c}\text { Charging for Electric } \\
\text { Vehicles } 11 \mathrm{k} \mathrm{W}\end{array}$ & 73 \\
\hline Photovoltaic $3.3 \mathrm{kWp}$ & 73 \\
\hline $\begin{array}{c}\text { Photovoltaic power plant } \\
0.5 \text { MWp }\end{array}$ & 1 \\
\hline Transformer $22 / 0.4 \mathrm{kV}$ & 2 \\
\hline \hline
\end{tabular}

The load used in households ranged from 3 to $10 \mathrm{KW}$. Within the simulation was the use of PV panel from the Canadian solar company. This panel was used in two variations, either as a photovoltaic power plant consisting of 11 units placed on the roof of the house or as one large $0.5 \mathrm{MW}$ power plant located in the field or on the roof of an industrial plant. Panel parameters are in Table 2.

Table 2 PV panel parameters

\begin{tabular}{cc}
\hline \hline PARAMETER & VALUE \\
\hline Nominal Max. Power (Pmax) & $300 \mathrm{~W}$ \\
\hline Opt. Operating Voltage (Vmp) & $32.5 \mathrm{~V}$ \\
\hline Opt. Operating Current (Imp) & $9.24 \mathrm{~A}$ \\
\hline Open Circuit Voltage (Voc) & $39.7 \mathrm{~V}$ \\
\hline Short Circuit Current (Isc) & $9.83 \mathrm{~A}$ \\
\hline Module Efficiency & $18.33 \%$ \\
\hline Operating Temperature & $-40^{\circ} \mathrm{C} \sim+85^{\circ} \mathrm{C}$ \\
\hline Max. System Voltage & $1000 \mathrm{~V}$ \\
\hline Module Fire Performance & or CLASS C (IEC \\
& $61730)$ \\
\hline Max. Series Fuse Rating & $15 \mathrm{~A}$ \\
\hline Application Classification & Class A \\
\hline Power Tolerance & $0 \sim+5 \mathrm{~W}$ \\
\hline \hline
\end{tabular}

The use of PV panel as a renewable electricity source was mainly due to the availability of these devices. If we wanted to compare the basic renewable sources and their application in the home, it would win the sun's energy. The installation of the heat pump requires higher input costs; the use of wind turbines would only be possible in island operation and without the use of subsidies. Geothermal energy is used to a very low extent in Slovakia, resulting in the necessary geological exploration of the subsoil and several hundred-meter wells. [5][6]

An electric vehicle charger with a power of $11 \mathrm{~kW}$ was also used in the analysis. The increasing number of chargers and their impact on the network was mainly due to planned changes in the EU legist. There is a presumption that in the approval of the house will be one of the conditions to install a charger for an electric car. These regulations are specifically described in the last European Directive 2014/94 / EU of 22 October 2014 on the deployment of alternative fuels infrastructure, but also in Directive 2009/28 / EC of the European Parliament and of the Council of 23 April 2009 on the promotion of the use of energy from renewable sources and also Directive 2010/31 / EU of the European Parliament and of the Council of 19 May 2010 on the energy performance of buildings. Based on these regulations, it was monitored whether such a network could cope with the onslaught. In the simulation, the assumption was that the network would be at a high degree of load and that charging cars would occur at the same time. [8] [9]

There are several charging profiles when charging. Most depend on the working time of the car owner and also on the length of the route he/she regularly attends. It is also possible to consider the use of e-car for the accumulation of electricity in the analyses.

\section{NETWORK ANALYSIS}

Two scenarios were used to verify the impact of smart grid elements on a small part of the distribution system. In both cases, chargers were connected step by step, and changes in the network were continuously monitored. During parameter monitoring, it was also possible to capture the moment when the network was overloaded.

The PV power plant is located in the middle of the village, closer to transformer number 2. This position should maintain network stability and also reduce losses. Placing on the periphery of the network might not have a positive impact on neighboring houses. There is also the assumption that the power lines do not have to be sized to connect such a source.

The scenario number one describes the state of the network when PV panels on the roof are not attached to the system and also a larger PV power plant. This condition may also be a condition where the solar radiation does not fall on the panels.

The scenario number two differs in that PV production is at full power. Such a state could also simulate the middle of the day when the sun is highest. As it is a village, this situation could occur mainly when most of the population is at home and working on their homes.

\subsection{Scenario 1}

In scenario one, both the measured values (Table 3 ) and the graphical representation of the results (Figure 2 and Figure 3) can be seen. In this case, we can see that the losses in the network without the use of chargers were only at the level of $\mathrm{kW}$ units. By gradually connecting the chargers, the network status began to change. In the table, we can see the critical number (45) of connected chargers when the network was overloaded.

If we wanted to evaluate the percentage chance of this situation in more detail, we would achieve a max $10 \%$ chance that this situation would happen. From the opposite point of view, from network operation, it should be stressed that such a situation cannot occur. 
Table 3 Parametres in scenario 1

\begin{tabular}{ccccc}
\hline $\begin{array}{c}\mathrm{N} . \\
-\end{array}$ & $\begin{array}{c}\text { P Loss } \\
\mathrm{kW}\end{array}$ & $\begin{array}{c}\text { Q Loss } \\
\mathrm{kVar}\end{array}$ & $\begin{array}{c}\text { P Imp } \\
\mathrm{kW}\end{array}$ & $\begin{array}{c}\text { Q Imp } \\
\mathrm{kVar}\end{array}$ \\
\hline \hline & 3.38 & 13.36 & 261.18 & 102.43 \\
\hline 4 & 4.73 & 18.16 & 309.83 & 120.61 \\
\hline 12 & 9.08 & 30.8 & 402.18 & 162.18 \\
\hline 20 & 13.11 & 45.5 & 494.21 & 205.81 \\
\hline 28 & 17.66 & 63.26 & 586.76 & 252.49 \\
\hline 36 & 24.46 & 86.19 & 681.56 & 304.36 \\
\hline 44 & 33.59 & 114.59 & 778.69 & 361.69 \\
\hline $\mathbf{4 5}$ & 35.75 & 121.25 & 800 & 374.64 \\
\hline 48 & 38.83 & 130.45 & 827.94 & 392 \\
\hline 58 & 48.03 & 168.49 & 947.13 & 466.2 \\
\hline 70 & 67.66 & 231.65 & 1098.76 & 572.76 \\
\hline 73 & 70.81 & 246.31 & 1134.92 & 598.27 \\
\hline $\mathrm{N}$. & $\mathrm{P} \mathrm{Gen}$ & $\mathrm{Q} \mathrm{Gen}$ & $\mathrm{P} \mathrm{Load}$ & $\mathrm{Q}$ Load \\
- & $\mathrm{kW}$ & $\mathrm{kVar}$ & $\mathrm{kW}$ & $\mathrm{kVar}$ \\
\hline \hline & 261.18 & 102.43 & 264.4 & 86.9 \\
\hline 4 & 309.83 & 120.61 & 308.4 & 101.37 \\
\hline 12 & 402.18 & 162.18 & 396.4 & 130.29 \\
\hline 20 & 494.21 & 205.81 & 484.4 & 159.22 \\
\hline 28 & 586.76 & 252.49 & 572.4 & 188.15 \\
\hline 36 & 681.56 & 304.36 & 660.4 & 217.08 \\
\hline 44 & 778.69 & 361.69 & 748.4 & 246.01 \\
\hline $\mathbf{4 5}$ & 800 & 374.64 & 767.55 & 252.3 \\
\hline 48 & 827.94 & 392 & 792.4 & 260.47 \\
\hline 58 & 947.13 & 466.2 & 902.4 & 296.63 \\
\hline 70 & 1098.76 & 572.76 & 1034.4 & 340.02 \\
\hline 73 & 1134.92 & 598.27 & 1067.4 & 350.87 \\
\hline \hline & & & & \\
\hline
\end{tabular}

In Figure 2, we can see losses of active power and reactive power. On figure 3 shows generated energy in the network when running scenario 1 . The upper curve shows reactive and lowers active losses. In both graphs, it is possible to see the break when network congestion occurs.

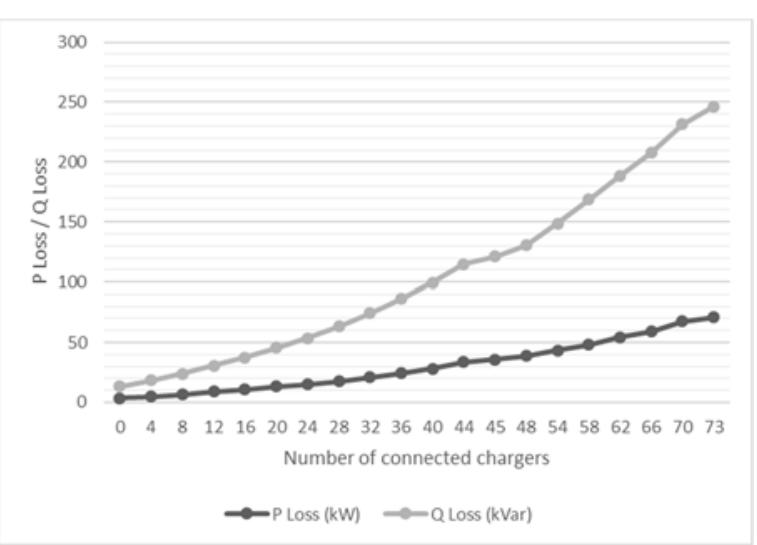

Fig. 2 Losses of active power and reactive power in the network when running scenario 1

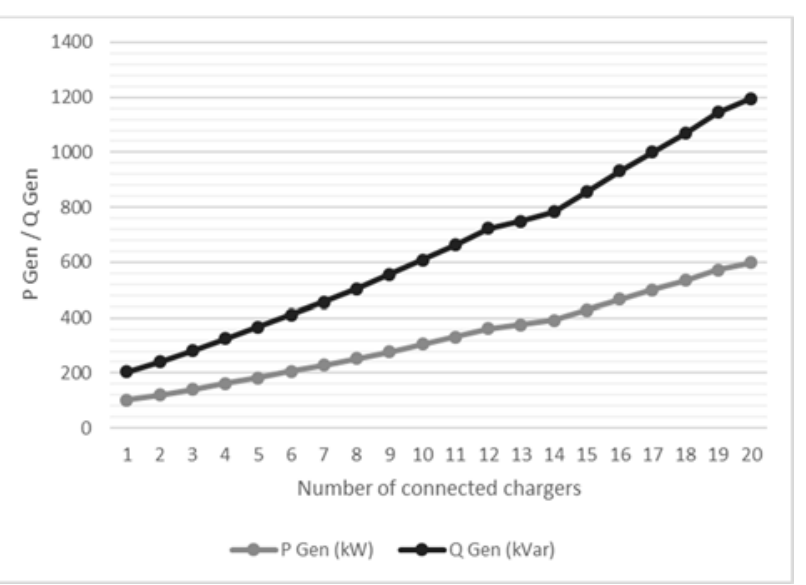

Fig. 3 Generated energy in the network when running scenario 1

Table 4 shows the results from scenario number two. The most fundamental change is that the losses compared to the first scenario are lower, and also the critical value of the connected chargers is higher (50) than in the first case.

Table 4 Parameters in scenario 2

\begin{tabular}{ccccc}
\hline \hline Numb. & $\begin{array}{c}\text { P Loss } \\
\text { kW }\end{array}$ & $\begin{array}{c}\text { Q Loss } \\
\text { kVar }\end{array}$ & $\begin{array}{c}\text { P Imp } \\
\text { kW }\end{array}$ & $\begin{array}{c}\text { Q Imp } \\
\text { kVar }\end{array}$ \\
\hline \hline 0 & 1.63 & 6.62 & 36.07 & 178.46 \\
\hline 4 & 2.18 & 8.17 & 74.54 & 192.48 \\
\hline 13 & 4.57 & 15.1 & 175.93 & 231.95 \\
\hline 21 & 7.17 & 24.39 & 266.53 & 270.18 \\
\hline 29 & 10.61 & 37.1 & 357.97 & 311.81 \\
\hline 33 & 13.08 & 45.08 & 404.43 & 334.26 \\
\hline 41 & 17.47 & 63.18 & 507.82 & 384.9 \\
\hline 49 & 23.34 & 83.1 & 593.54 & 431.07 \\
\hline $\mathbf{5 0}$ & 24.34 & 86.21 & 605.54 & 437.8 \\
\hline 53 & 27.22 & 93.83 & 630.42 & 452.65 \\
\hline 61 & 36.27 & 124.7 & 738.48 & 516.06 \\
\hline 69 & 44.29 & 152.5 & 823.49 & 569.17 \\
\hline 73 & 48.21 & 168.69 & 871.41 & 599.83 \\
\hline \hline Numb. & P Gen & Q Gen & P Load & Q Load \\
- & $\mathrm{kW}$ & $\mathrm{kVar}$ & $\mathrm{kW}$ & $\mathrm{kVar}$ \\
\hline \hline 0 & 36.07 & 178.46 & 278.64 & 91.58 \\
\hline 4 & 74.54 & 192.48 & 316.55 & 104.04 \\
\hline 13 & 175.93 & 231.95 & 415.55 & 136.59 \\
\hline 21 & 266.53 & 270.18 & 503.55 & 165.52 \\
\hline 29 & 357.97 & 311.81 & 591.55 & 194.45 \\
\hline 33 & 404.43 & 334.26 & 635.55 & 208.91 \\
\hline 41 & 507.82 & 384.9 & 734.55 & 241.45 \\
\hline 49 & 593.54 & 431.07 & 814.4 & 267.7 \\
\hline $\mathbf{5 0}$ & 605.54 & 437.8 & 825.4 & 271.32 \\
\hline 53 & 630.42 & 452.65 & 847.4 & 278.55 \\
\hline 61 & 738.48 & 516.06 & 946.4 & 311.09 \\
\hline 69 & 823.49 & 569.17 & 1023.4 & 336.41 \\
\hline 73 & 871.41 & 599.83 & 1067.4 & 350.87 \\
\hline & & & & \\
\hline & & & & \\
\hline 4
\end{tabular}


Figure 4 and Figure 5 show losses as well as energy produced. By examining the graphs, we can see the break when congestion occurred, and also the maximum values are lower than in scenario one.

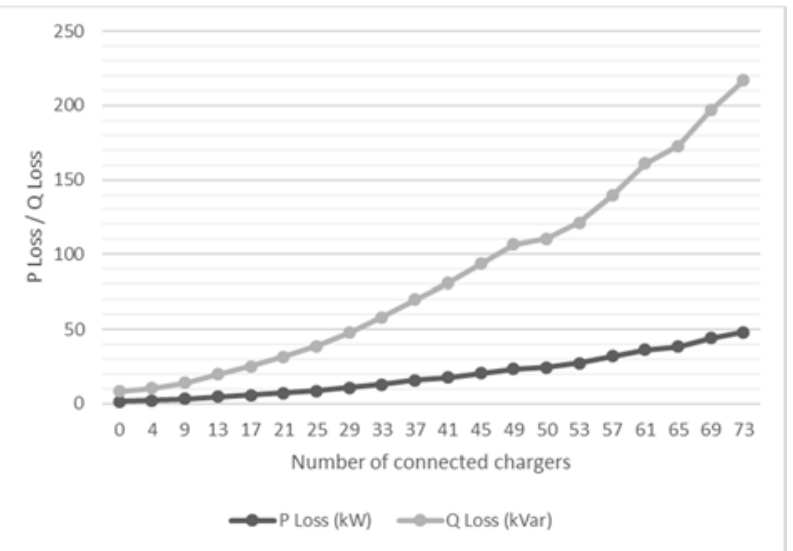

Fig. 4 Losses of active power and reactive power in the network when running scenario 2

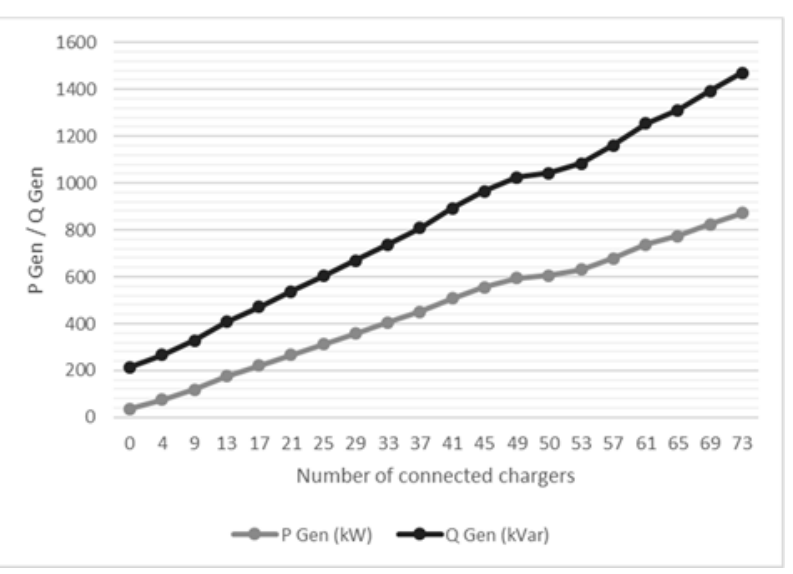

Fig. 5 Generated energy in the network when running scenario 2

\section{CONCLUSIONS}

This paper compares the impact of electromobility on microgrid that was modelled based on real data. Modelling has proposed the use of renewable electricity sources (RES), specifically PV panels, to reduce the power consumption of the network. Within the evaluation, it is possible to compare two scenarios that are evaluated in both numerical and graphical form. It follows from that article that the use of the RES has a significant effect on such a small system. The use of PV panels has significantly reduced network losses regardless of losses in the higher voltage system and also in the transmission system.

This proposal can be further improved, e.g., o adding another renewable resource that would assist in network operation when solar radiance does not fall on PV panels. By increasing the power of the PV farm, the use of batteries could be considered as a way of accumulating electricity.

This simulation is only approximate as the software offers only limited possibilities to simulate network behaviour. Used values are static, and it would be better to use time-varying data. If we wanted to be more precise, it would be necessary to simulate the change of load during the day. It would also be necessary to simulate the course of solar radiation during the day in different conditions and different seasons. E-car charging itself could then be divided into different parts of the day based on charging scenarios.

Finally, smart grids play an important role now. Currently, we can only perceive it through smart metering, but several pilot projects are already running not only abroad but also in our country. Even this paper can be a small grain of sand in the desert of smart grids.

\section{ACKNOWLEDGMENTS}

This work was supported by the Scientific Grant Agency of the Ministry of Education of Slovak Republic and the Slovak Academy of Sciences by the projects VEGA No. $1 / 0372 / 18$.

\section{REFERENCES}

[1] VOLČKO V.: Smart grid - vplyv na prevádzku, bezpečnost' a stabilitu elektrizačnej sústavy, FEI STU, $26 \quad$ p., 2015, online: https://www.fei.stuba.sk/buxus/docs/2015/autorefera ty/Volcko autoref.pdf

[2] VOJTEK, M. - KOLCUN, M. - MIKITA, M. - SPES, M.: Integration of photovoltaic and wind power plants in low voltage networks using energy storages. (Technical University of Kosice, 2017).

[3] KANALIK, M. - PAVLIK, M. - KOLCUN, M.: The Impact of Multi-system Overhead Lines Operation with Different Voltage Levels to Voltage Unbalance. (Technical University of Kosice, 2015).

[4] HOCKO, P. - NOVAK, M. - KOLCUN, M. CONKA, Z.: Influence of photovoltaic power plants on the power system to the prediction for year 2020 . (IEEE, 2014).

[5] BORLASE S.: Smart Grids: Infrastructure, Technology and Solutions. CRC, 2013, 577 p.

[6] MOMOH J.: Smart Grid: Fundamentals of Design and Analysis, IEEE P., 2012, 216 p.

[7] SIOSHANSI F. P., Smart Grid: Integrating Renewable, Distributed \& Efficient Energy. Academic Press, 2011. 510 p. ISBN 978-0-12386452-4

[8] Directive 2014/94/EU of the European Parliament and of the Council of 22 October 2014 on the deployment of alternative fuels infrastructure Text with EEA relevance, online: https://eur-lex.europa.eu/legalcontent/EN/TXT/?uri=celex\%3A32014L0094.

[9] DIRECTIVE 2010/31/EU OF THE EUROPEAN PARLIAMENT AND OF THE COUNCIL of 19 May 2010on the energy performance of buildings. Online: https://eur-lex.europa.eu/legalcontent/EN/TXT/HTML/?uri=CELEX:32010L0031 $\&$ from $=\mathrm{SK}$. 
Received October 2, 2019, accepted November 13, 2019

\section{BIOGRAPHIES}

Michal Ivančák was born in 1993. In 2016 graduated (Ing.) at the Department of Electrical Power Engineering on the Faculty of Electrical Engineering and Informatics at Technical University of Košice. At present he is a Ph.D. student in the Department of Electrical Power Engineering on the Faculty of Electrical Engineering and Informatics at Technical University of Košice. He received a master's degree in electric power engineering on subject of the selectivity analysis for electrical balance of power plant with coordination with ABB. His scientific research is mainly focused on research of smart grid.

Juraj Kurimský was born in 1967. In 1990 graduated (Ing.) at the Department of Electrical Power Engineering on the Faculty of Electrical Engineering and Informatics at Technical University of Košice. He received the PhD. degree in electrical power engineering from the Faculty of Electrical Engineering and Informatics at Technical University of Košice. He is associate professor at Technical university of Košice. His research interests concern: discharges in transformers, analysis of partial discharges.

Jakub Urbanský was born in 1991. In 2017 graduated (Ing.) at the Department of Electrical Power Engineering on the Faculty of Electrical Engineering and Informatics at Technical University of Košice. At present is a Ph.D. student in the Department of Electrical Power Engineering on the Faculty of Electrical Engineering and Informatics at Technical University of Košice. He received a master degree in electric power engineering on subject of the integration of electric vehicle into the electrical power distribution, using the vehicles-to-grid (V2G) technology. His scientific research is mainly focused on research of renewables. 